\title{
Exercise intensity of robot-assisted walking versus overground walking in nonambulatory stroke patients
}

\author{
Michiel P. M. van Nunen, MSc; ${ }^{1-2 *}$ Karin H. L. Gerrits, PhD; ${ }^{1-2}$ Arnold de Haan, PhD; ${ }^{1,3}$ Thomas W. J. \\ Janssen, $\mathbf{P h D}^{\mathbf{1 - 2}}$ \\ ${ }^{1}$ Research Institute MOVE, Vrije Universiteit Amsterdam, Amsterdam, the Netherlands, ${ }^{2}$ Amsterdam Rehabilitation \\ Research Center/Reade, Amsterdam, the Netherlands; ${ }^{3}$ Institute for Biomedical Research into Human Movement and \\ Health, Manchester Metropolitan University, Manchester, United Kingdom
}

\begin{abstract}
It has been suggested that aerobic training should be considered in stroke rehabilitation programs to counteract detrimental health effects and decrease cardiovascular risk caused by inactivity. Robot-assisted treadmill exercise (using a Lokomat device) has the potential to increase the duration of walking therapy relative to conventional overground therapy. We investigated whether exercise intensity during Lokomat therapy is adequate to elicit a training effect and how assistance during walking in the Lokomat affects this exercise intensity. Ten patients with stroke (age $54+/-9$ yr) walked in both the Lokomat and in a hallway. Furthermore, 10 nondisabled subjects (age $43+/-14$ yr) walked in the Lokomat at various settings and on a treadmill at various speeds. During walking, oxygen consumption and heart rate were monitored. Results showed that for patients with stroke, exercise intensity did not reach recommended levels (30\% heart rate reserve) for aerobic training during Lokomat walking. Furthermore, exercise intensity during walking in the Lokomat $(9.3+/-1.6 \mathrm{~mL} / \mathrm{min} / \mathrm{kg})$ was lower than during overground walking $(10.4+/-1.3 \mathrm{~mL} /$ $\mathrm{min} / \mathrm{kg}$ ). Also, different settings of the Lokomat only had small effects on exercise intensity in nondisabled subjects.
\end{abstract}

Key words: aerobic training, exercise intensity, heart rate, hemiplegia, locomotor training, oxygen consumption, rehabilitation therapy, robot-assisted walking, stroke, walking.

\section{INTRODUCTION}

A large portion of patients with stroke initially has no walking ability and cannot walk independently because of hemiparesis and compromised balance. Moreover, a subgroup of patients with stroke is not able to walk independently even after a few months into the rehabilitation process. The inability to walk independently or be active has been suggested to lead to further deconditioning and is related to balance [1]. Secondary impairments, such as muscle atrophy and reduced aerobic capacity, have been reported and suggested to contribute to further functional declines in gait [2]. To counteract detrimental health effects and to decrease cardiovascular risk caused by inactivity, it has been suggested that aerobic training should be considered in stroke rehabilitation programs [3-6]. Although there are probably differences among approaches in different countries and different rehabilitation centers, both Kuys et al. [7] and MacKay-Lyons and Makrides [4]

\footnotetext{
Abbreviations: ACSM = American College of Sports Medicine, ANOVA $=$ analysis of variance, $\mathrm{BBS}=$ Berg Balance Scale, bpm = beats per minute, BWS = body-weight support, $\mathrm{CI}=$ confidence interval, CWS = comfortable walking speed, FAC = Functional Ambulation Category, GF = guidance force, HR = heart rate, $\mathrm{HRR}=$ heart rate reserve, $\mathrm{MET}=$ metabolic equivalent of task, $\mathrm{VO}_{2}=$ oxygen consumption.

*Address all correspondence to Michiel P. M. van Nunen, MSc; Vrije Universiteit Amsterdam, Research Institute MOVE, Van der Boechorststraat 9, Amsterdam 1081 BT, the Netherlands; +31-61-98-78294; fax: + 31-20-59-88529. Email: m.vannunen@fbw.vu.nl http://dx.doi.org/10.1682/JRRD.2011.12.0252
} 
showed that contemporary stroke rehabilitation programs in Canada and Australia did not elicit adequate exercise intensity for aerobic training.

In recent years, a device for robot-assisted gait therapy (Lokomat, Hocoma AG; Volketswil, Switzerland) was developed to automate body-weight supported treadmill training for severely disabled patients. The Lokomat consists of a treadmill with a body-weight support (BWS) system and two robotic orthoses that guide the patient's legs, allowing he or she to walk for longer duration and making more repetitions possible during therapy [5]. Several studies have investigated the effectiveness of the Lokomat in restoring walking ability [8-10]. However, there is a lack of studies related to exercise intensity of Lokomat therapy and the potential for facilitating aerobic training in severely affected patients with stroke.

Walking in the Lokomat has been shown to increase oxygen consumption $\left(\mathrm{VO}_{2}\right)$ above resting levels in patients and nondisabled subjects without experience walking in the Lokomat, indicating that walking in the Lokomat is not passive [11]. It is, however, still largely unknown whether exercise intensity of walking in the Lokomat during the rehabilitation process of patients with stroke is within levels of intensity for aerobic training as recommended by the American College of Sports Medicine (ACSM) [12]. Furthermore, little knowledge exists about how assistance during walking in the Lokomat influences exercise intensity of walking, e.g., in severely affected patients. Walking speed in the Lokomat can be much faster than during overground walking. From the literature, it is known that walking at a higher speed requires more energy [13-14], and therefore, one could expect exercise intensity to increase during Lokomat walking compared with overground walking. However, BWS has been shown to decrease $\mathrm{VO}_{2}$ during treadmill walking [15]. Also, the Lokomat assists the legs during walking, potentially decreasing exercise intensity [16]. Finally, during walking in the Lokomat, the position of the pelvis is held constant relative to the treadmill, thereby decreasing the horizontal propulsion force and, at the same time, decreasing energy cost during walking [14]. Combined, these factors complicate predictions of effects of assistance on exercise intensity during Lokomat walking.

To improve our understanding of the exercise intensity of Lokomat walking during therapy, our primary objective was to investigate the exercise intensity during Lokomat therapy and compare this with exercise inten- sity recommendations of the ACSM. The second objective was to compare exercise intensity of walking in the Lokomat with normal overground gait in patients with stroke. Since patients can walk for longer duration in the Lokomat and the device provides assistance during walking, we hypothesized that patients with stroke walking in the Lokomat walked at lower exercise intensity than during normal gait. The third objective was to evaluate how different settings of the Lokomat affect exercise intensity during walking on the device. We hypothesized that increased assistance decreases exercise intensity of walking in the Lokomat.

\section{METHODS}

\section{General Design}

Participants came to the laboratory to perform two experimental sessions: walking in the Lokomat and walking in a hallway. Nondisabled subjects performed one experimental session consisting of Lokomat walking and another of unassisted walking on a treadmill. We collected cardiorespiratory parameters during each walking session.

\section{Lokomat}

The design and control of the Lokomat has been reported previously [7]. In this study, we used the LokomatPro device (Hocoma AG) with the Levi BWS system. In all trials for both patients with stroke and nondisabled subjects, the Levi BWS system was activated. Three settings were manipulated during this study: speed; amount of BWS; and guidance force (GF), which is the amount of assistance of the robotic orthoses.

\section{Subjects}

Ten patients with hemiplegic stroke (6 male and 4 female; age $54 \pm 9 \mathrm{yr}$ ) and ten nondisabled subjects (6 male and 4 female; age $43 \pm 14 \mathrm{yr}$ ) participated in the study (all units are mean \pm standard deviation unless otherwise specified). Patients had a first-ever stroke and no unstable hypertension, no unstable cardiovascular problems, no severe skeletal problems, and no severe cognitive and/or communicative problems preventing the ability to follow verbal instructions. Table 1 presents patient characteristics such as age, sex, lesion side, and time poststroke. Functional limitations are described using Functional Ambulation Category (FAC) and the Berg 
Table 1.

Characteristics of patients with stroke.

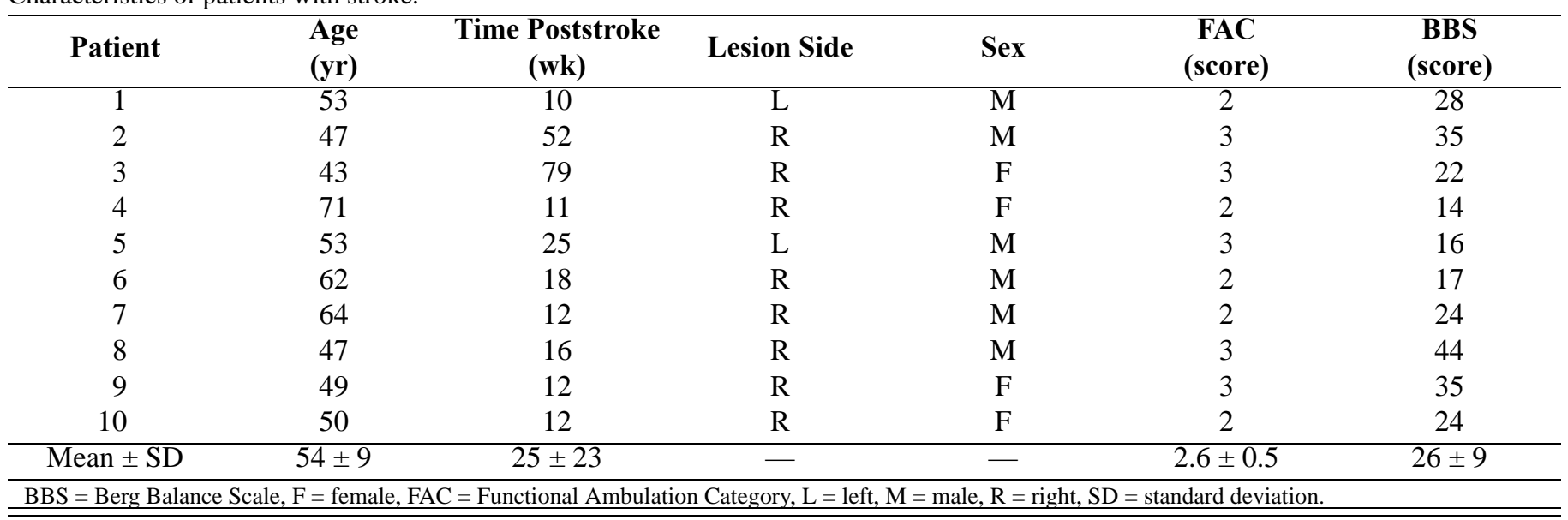

Balance Scale (BBS). The FAC score is a 6-point measure for walking ability [17-18]; FAC scores $<3$ indicate dependent walking ability, while a score of 3 indicates supervision needed. The BBS, developed to qualitatively asses balance, consists of 14 test items scored on a 5point ordinal scale [19].

All patients with stroke had already received therapy in the Lokomat at least seven times before the first measurements were performed. Eight patients had been training on the Lokomat as part of their inpatient treatment to improve walking ability. We asked two patients to participate in the study after their discharge from the rehabilitation center. Patients were, therefore, familiar with walking in the Lokomat and settings were fine-tuned to their capabilities. In this study, nondisabled subjects had at least two practice sessions of $30 \mathrm{~min}$ in the Lokomat to familiarize themselves with walking in the device with various combinations of speed, BWS, and GF.

\section{General Procedures}

We measured $\mathrm{VO}_{2}$ and heart rate (HR) as indices of cardiorespiratory responses. During the Lokomat and treadmill trials, we continuously monitored $\mathrm{VO}_{2}$ with an Oxycon Alpha (Med Point-Jaeger; Boulder, Colorado). During the overground trials of all participants, we used an Oxycon Mobile lightweight portable spirometer (Med Point-Jaeger) to measure $\mathrm{VO}_{2}$. This portable system attaches to the chest with a comfortable vest $(1.1 \mathrm{~kg})$. We continuously monitored HR with an HR monitor (Polar RS400, Polar Electro; Kempele, Finland).

\section{Experimental Protocol and Data Analyses}

\section{Patients with Stroke}

During the experiments, we strapped the paretic arm using an arm sling as a precaution to prevent shoulder pain. We measured baseline resting $\mathrm{VO}_{2}$ in the seated position for $3 \mathrm{~min}$. After preparation for Lokomat therapy, patients with stroke walked in the Lokomat while we monitored $\mathrm{VO}_{2}$ and $\mathrm{HR}$. Lokomat settings were the same as those used for the patients' regular therapy settings and were individually optimized in such a way that they walked at a comfortable walking speed (CWS) with GF of the device kept at a minimum level and appropriate BWS without knee buckling during the stance phase. We used settings from previous therapy sessions as reference settings for the trials in the Lokomat and adjusted settings if necessary.

Before patients with stroke performed overground walking, we measured baseline resting $\mathrm{VO}_{2}$ during sitting for $3 \mathrm{~min}$. Subsequently, we instructed patients to walk at their CWS along a $20 \mathrm{~m}$ walkway. A physical therapist walked closely behind the patients for either supervision or assistance in maintaining balance. After $20 \mathrm{~m}$, patients turned and walked down the walkway in the opposite direction. Patients walked for 6 min continuously before sitting down or until they needed to sit down because walking became too strenuous. All patients with stroke walked with their usual aids for overground walking: a quad cane and an ankle foot orthosis.

We averaged recorded $\mathrm{VO}_{2}$ and $\mathrm{HR}$ data over $60 \mathrm{~s}$ intervals. We determined $\mathrm{VO}_{2}$ during rest $\left(\mathrm{VO}_{2 \text { rest }}\right)$, highest $\mathrm{VO}_{2}$ during the session $\left(\mathrm{VO}_{2 \text { peak }}\right)$, and average 
$\mathrm{VO}_{2}$ over the interval between minute 3 and the last minute of walking $\left(\mathrm{VO}_{2 \mathrm{avg}}\right)$ during both Lokomat and overground walking and expressed them in both absolute values and in metabolic equivalents of task (METs). We computed METs using the formula $\mathrm{VO}_{2} / \mathrm{VO}_{2 \text { rest }}$. Variables associated with $\mathrm{HR}$ were the lowest $\mathrm{HR}$ during rest $\left(\mathrm{HR}_{\text {rest }}\right)$, $\mathrm{HR}$ at $\mathrm{VO}_{2 \text { peak }}\left(\mathrm{HR}_{\text {peak }}\right)$, and average $\mathrm{HR}$ $\left(\mathrm{HR}_{\mathrm{avg}}\right)$.

We estimated exercise intensity using the Karvonen method, with the HR reserve (HRR) being the difference between $\mathrm{HR}_{\text {rest }}$ and the age-predicted maximal HR, estimated using the formula $\mathrm{HR}_{\max }=220-$ age. For the patient using beta-blocking medication $(n=1)$, we adjusted the formula to $\mathrm{HR}_{\text {max-beta }}=0.85 \times(220-$ age $)$ $[4,20]$. We estimated exercise intensity by expressing the HR relative to HRR (\%HRR) [12]. ACSM guidelines for sedentary/extremely deconditioned nondisabled adults recommend training at a \%HRR of 30 to 45 percent [12]. Both $\mathrm{HR}_{\mathrm{avg}}$ and $\mathrm{HR}_{\text {peak }}$ were expressed as \%HRR and compared with these recommendations.

\section{Nondisabled Control Subjects}

Since patients with stroke are not capable of walking in the Lokomat at any combination of settings possible, we studied the effects of settings of the Lokomat in nondisabled subjects only. We measured resting $\mathrm{VO}_{2}$ during 3 min of seated rest. Nondisabled subjects walked in the Lokomat at eight combinations of settings, similar to those used during rehabilitation of patients with stroke. We set speed at either 1.7 or $2.2 \mathrm{~km} / \mathrm{h}$, GF at either 50 or 20 percent, and BWS at either 50 or 25 percent of body weight, resulting in eight $(2 \times 2 \times 2)$ different conditions. After the Lokomat trials, nondisabled subjects rested a few minutes. The nondisabled subjects subsequently walked on a treadmill, performing four walking trials at different treadmill speeds $(0.7,1.1,1.7$, and $2.2 \mathrm{~km} / \mathrm{h})$. All trials were performed for $3 \mathrm{~min}$. We further analyzed minimal HR during rest $\left(\mathrm{HR}_{\text {rest }}\right)$ and average $\mathrm{VO}_{2}$ and HR during the last minute of all the Lokomat and treadmill-only trials. The formulas used to estimate \%HRR were also used to determine exercise intensity in nondisabled subjects.

\section{Statistical Analysis}

We tested data for normality using Shapiro-Wilk tests. We performed paired $t$-tests to investigate whether exercise intensity (as measured with $\mathrm{VO}_{2}$ and \%HRR) of Lokomat walking was different from normal overground gait in patients with stroke. To study the effects of several combinations of settings of the Lokomat on $\mathrm{VO}_{2}$ or \%HRR, we performed a three-way repeated measures analysis of variance (ANOVA) with within-factors BWS ( $25 \%$ or $50 \%)$, GF $(20 \%$ or $50 \%)$, and speed (1.7 or $2.2 \mathrm{~km} / \mathrm{h}$ ) on the Lokomat trials only. Furthermore, we performed two ANOVAs on whether a difference existed in $\mathrm{VO}_{2}$ or \%HRR between trials performed at the same speed with or without the assistance of the Lokomat. In these two ANOVAs, we compared four Lokomat trials with the treadmill trial at the same speed for 1.7 and $2.2 \mathrm{~km} / \mathrm{h}$, respectively. We performed post hoc analyses using paired $t$-tests with Bonferroni correction when appropriate.

To evaluate whether patients with stroke and nondisabled subjects responded in a similar manner to Lokomat assistance, we performed a two-way (mixed-design) ANOVA on $\mathrm{VO}_{2}$ and \%HRR data with a betweensubject factor "group" (patients with stroke and nondisabled subjects) and a within-subject factor "mode of walking" (Lokomat or no Lokomat). During the overground trial of patients with stroke, the average speed was $0.7 \pm 0.2 \mathrm{~km} / \mathrm{h}$. For comparison, the trials for nondisabled subjects included in this analysis were the trials with walking speed at $0.7 \mathrm{~km} / \mathrm{h}$ for normal walking and the Lokomat trial with theoretically the least device assistance (settings: $2.2 \mathrm{~km} / \mathrm{h}, 25 \%$ BWS, and 20\% GF), since these trials were the most comparable with the trials performed by patients with stroke. We tested homogeneity of variances using the Levene test for homogeneity of variances. Finally, we performed a $t$-test to investigate whether $\mathrm{VO}_{2}$ during Lokomat walking was similar for both groups. We considered probability values of $<0.05$ significant. We performed all analyses using PASW version 18.0 for Windows (SPSS, IBM Corporation; Armonk, New York).

\section{RESULTS}

\section{Exercise Intensity of Lokomat Walking for Patients with Stroke}

Table 2 shows a summary of the characteristics of the trials performed by all participants. Of the 10 patients with stroke, 1 showed an individual exercise intensity $>30 \%$ HRR. For patients with stroke, exercise intensity expressed in METs was within the range defined as light physical activity intensity for the lowest fitness level group according to ACSM guidelines. 
Table 2.

Performance parameters during overground (patients with stroke) and Lokomat (nondisabled subjects) trials (mean \pm standard deviation).

\begin{tabular}{|c|c|c|}
\hline Parameter & Overground & Lokomat \\
\hline$\overline{\text { Velocity }}_{\text {peak }}(\mathrm{km} / \mathrm{h})$ & $0.7 \pm 0.2$ & $2.1 \pm 0.1$ \\
\hline BWS $_{\text {peak }}(\%)$ & 一 & $33 \pm 9$ \\
\hline $\mathrm{GF}_{\text {peak }}(\%)$ & 一 & $29 \pm 6$ \\
\hline Endurance (min) & $5.1 \pm 0.8$ & $26.0 \pm 5.0$ \\
\hline $\mathrm{VO}_{2 \text { peak }}(\mathrm{mL} / \mathrm{min} / \mathrm{kg})$ & $10.4 \pm 1.3$ & $9.3 \pm 1.6$ \\
\hline $\mathrm{VO}_{\text {2avg }}(\mathrm{mL} / \mathrm{min} / \mathrm{kg})$ & $9.9 \pm 1.4$ & $7.8 \pm 1.5$ \\
\hline $\mathrm{HR}_{\text {peak }}(\mathrm{bpm})$ & $104 \pm 14$ & $92 \pm 12$ \\
\hline $\mathrm{HR}_{\mathrm{avg}}(\mathrm{bpm})$ & $104 \pm 13$ & $89 \pm 13$ \\
\hline MET & $2.8 \pm 0.3$ & $2.1 \pm 0.3$ \\
\hline$\% H_{\text {peak }}$ & $38 \pm 13$ & $25 \pm 7$ \\
\hline$\% \mathrm{HRR}_{\mathrm{avg}}$ & $38 \pm 12$ & $22 \pm 7$ \\
\hline
\end{tabular}

All variables and differences were normally distributed. In patients with stroke, the peak $\mathrm{VO}_{2}$ during overground walking $(10.4 \pm 1.3 \mathrm{~mL} / \mathrm{min} / \mathrm{kg})$ was significantly higher than during Lokomat walking for nondisabled subjects $(9.3 \pm 1.6 \mathrm{~mL} / \mathrm{min} / \mathrm{kg} ; t(9)=2.83 ; p<0.02$; mean difference $\mathrm{VO}_{2}: 1.1 \mathrm{~mL} / \mathrm{min} / \mathrm{kg}, 95 \%$ confidence interval [CI]: 0.2-1.9). Correspondingly, $\mathrm{HR}_{\text {peak }}$ during overground walking for patients with stroke $(104 \pm 14$ beats per minute [bpm]) was significantly higher than during Lokomat walking for nondisabled subjects (92 \pm 12 bpm; $t(9)=2.59 ; p<0.03$; mean difference HR: 12.4 bpm, 95\% CI: 1.5-23.2).

\section{Effects of Settings of Lokomat on Exercise Intensity}

For nondisabled subjects, Table 3 shows $\mathrm{VO}_{2}$ and HR during all trials with corresponding Lokomat settings. Average $\mathrm{VO}_{2}$ and $\mathrm{HR}$ values during different Lokomat settings were very similar for all eight settings (L1-L8) and for the normal gait treadmill trials (N1-N4).

The three-way $(2 \times 2 \times 2)$ repeated measures ANOVA revealed a significantly higher effect for lower GF on $\mathrm{VO}_{2}\left(F(1,9)=6.84 ; p<0.03 ; \eta^{2}=0.43\right)$ and $\mathrm{HR}$ $\left(F(1,9)=8.57 ; p<0.02 ; \eta^{2}=0.49\right)$. When GF was set at 20 percent, mean $\mathrm{VO}_{2}$ was $0.57 \mathrm{~mL} / \mathrm{min} / \mathrm{kg}$ higher $(95 \%$ CI: 0.08-1.06) and mean HR was $1.9 \mathrm{bpm}$ higher (95\% CI: 0.4-3.4) than during GF at 50 percent. Furthermore, there was a borderline significant interaction effect of BWS and speed in HR data $\left(F(1,9)=5.20 ; p<0.049 ; \eta^{2}=\right.$ 0.37 ) indicating that when BWS was 50 percent, walking at $2.2 \mathrm{~km} / \mathrm{h}$ elicited a higher HR than at $1.7 \mathrm{~km} / \mathrm{h}$, whereas when the BWS was 25 percent, walking at $2.2 \mathrm{~km} / \mathrm{h}$ elicited a lower HR than at $1.7 \mathrm{~km} / \mathrm{h}$. However, the differences between means were small (e.g., maximal difference was $2.3 \mathrm{bpm}$ ); therefore, the interaction effect had a small effect size.

The ANOVAs comparing trials performed at similar speeds (4 Lokomat trials and 1 treadmill-only trial at 1.7 or $2.2 \mathrm{~km} / \mathrm{h}$, respectively) showed comparable results. There were no significant differences in $\mathrm{VO}_{2}(F(2.6,23.8)=1.58$; $\left.p>0.05 ; \eta^{2}=0.15\right)$ and $\operatorname{HR}(F(2.4,21.7)=2.83 ; p>0.05$; $\left.\eta^{2}=0.24\right)$ between trials with walking speed at $1.7 \mathrm{~km} / \mathrm{h}$.

Table 3.

Settings with corresponding oxygen consumption $\left(\mathrm{VO}_{2}\right)$ and heart rate (HR) during Lokomat walking (L1-L8) and treadmill-only walking (N1-N4).

\begin{tabular}{|c|c|c|c|c|c|}
\hline Trial & BWS (\%) & $\begin{array}{c}\text { Speed } \\
(\mathrm{km} / \mathrm{h})\end{array}$ & GF (\%) & $\begin{array}{c}\dot{\mathrm{VO}} \mathrm{O}_{2}, \mathrm{~mL} / \mathrm{min} / \mathrm{kg} \\
(\text { mean } \pm \mathrm{SD})\end{array}$ & $\begin{array}{c}\text { HR, bpm } \\
(\text { mean } \pm \text { SD })\end{array}$ \\
\hline Rest & - & - & - & $3.7 \pm 0.4$ & $60 \pm 8$ \\
\hline L1 & 50 & 1.7 & 50 & $7.9 \pm 2.6$ & $76 \pm 10$ \\
\hline L3 & 50 & 2.2 & 50 & $7.9 \pm 1.7$ & $78 \pm 10$ \\
\hline L4 & 50 & 2.2 & 20 & $8.4 \pm 2.2$ & $79 \pm 13$ \\
\hline L7 & 25 & 2.2 & 50 & $8.0 \pm 1.4$ & $76 \pm 13$ \\
\hline L8 & 25 & 2.2 & 20 & $8.2 \pm 1.8$ & $77 \pm 12$ \\
\hline N1 & - & 0.7 & - & $7.0 \pm 1.0$ & $72 \pm 9$ \\
\hline N2 & - & 1.1 & - & $7.1 \pm 0.8$ & $74 \pm 10$ \\
\hline
\end{tabular}


$\mathrm{VO}_{2}$ at this speed was $8.2 \pm 1.7 \mathrm{~mL} / \mathrm{min} / \mathrm{kg}$ and $\mathrm{HR}$ was $77 \pm 9 \mathrm{bpm}$. Similarly, at $2.2 \mathrm{~km} / \mathrm{h}$ there were also no significant differences in $\mathrm{VO}_{2}(F(1.9,16.7)=1.25 ; p>0.05$; $\left.\eta^{2}=0.12\right)$ and $\operatorname{HR}\left(F(4,36)=0.92 ; p>0.05 ; \eta^{2}=0.09\right)$. $\mathrm{VO}_{2}$ at this speed was $8.2 \pm 1.4 \mathrm{~mL} / \mathrm{min} / \mathrm{kg}$ and $\mathrm{HR}$ was $78 \pm$ $11 \mathrm{bpm}$. This indicates that, although nondisabled subjects were assisted by the Lokomat, exercise intensity was not different from normal unassisted walking when walking at the same speeds.

\section{Exercise Intensity During Walking in Patients with Stroke Versus Nondisabled Subjects}

As a group, patients with stroke had a significantly higher $\mathrm{VO}_{2}(9.8 \mathrm{~mL} / \mathrm{min} / \mathrm{kg} ; 95 \% \mathrm{CI}$ : 9.0-10.6) than nondisabled subjects $(7.6 \mathrm{~mL} / \mathrm{min} / \mathrm{kg}$; $95 \% \mathrm{CI}$ : $6.8-8.5)$ across different modes of walking $(F(1,18)=15.67 ; p<$ $\left.0.001 ; \eta^{2}=0.47\right)$ (Figure). There was no significant difference between $\mathrm{VO}_{2}$ during Lokomat walking and normal gait for the whole group $\left(F(1,18)=0.36 ; p>0.05 ; \eta^{2}=\right.$ 0.002). There was, however, a significant interaction between mode of walking and group $(F(1,18)=11.21$; $p<$ $\left.0.005 ; \eta^{2}=0.38\right)$. Results of the analysis for \%HRR were similar; i.e., patients with stroke had significantly higher \%HRR (31.4\% HRR, 95\% CI: 27-36) than nondisabled subjects $(12.3 \%$ HRR, 95\% CI: 8-16) $(F(118)=$ 45.40; $\left.p<0.001 ; \eta^{2}=0.72\right)$ (Figure). There was no significant main effect for mode of walking $(F(1,18)=2.80$; $p>0.05 ; \eta^{2}=0.13$ ), but there was a significant interaction between mode of walking and group $(F(1,18)=$ $\left.12.00 ; p<0.005 ; \eta^{2}=0.4\right)$. These statistical results confirm what the Figure indicates: patients with stroke responded differently than nondisabled subjects with different types of walking; i.e., while patients with stroke showed a lower $\mathrm{VO}_{2}$ and \%HRR during Lokomat walking, the nondisabled subjects showed higher values during Lokomat walking than during treadmill walking at $0.7 \mathrm{~km} / \mathrm{h}$. Subsequent analysis showed no significant difference in $\mathrm{VO}_{2}$ during Lokomat walking in patients with stroke $\left(\mathrm{VO}_{2}: 9.3 \pm 1.6 \mathrm{~mL} / \mathrm{min} / \mathrm{kg}\right)$ compared with nondisabled subjects $\left(\mathrm{VO}_{2}: 8.2 \pm 1.8 \mathrm{~mL} / \mathrm{min} / \mathrm{kg}\right)(t(18)=$ $-1.36 ; p>0.05$; mean difference $\mathrm{VO}_{2}: 1.0 \mathrm{~mL} / \mathrm{min} / \mathrm{kg}$; 95\% CI: -0.6 to 2.6), indicating that VO during walking in the Lokomat was similar for patients with stroke and nondisabled subjects.

\section{DISCUSSION}

In this study, we compared exercise intensity of walking in the Lokomat with exercise intensity of normal gait in both patients with stroke and nondisabled subjects. Results indicate that the exercise intensity in patients with stroke was below levels recommended by the ACSM for sedentary/extremely deconditioned nondisabled adults

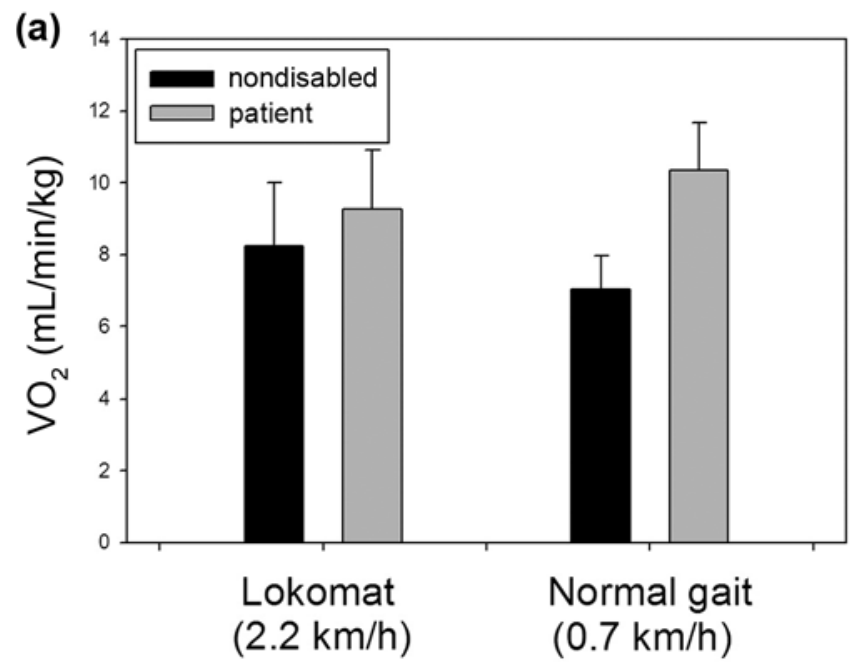

Participants

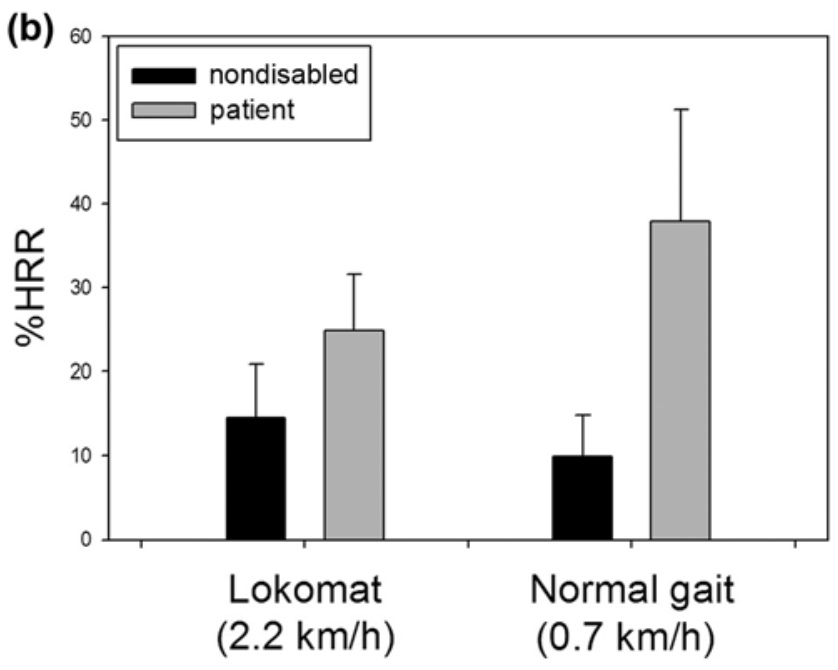

Participants

Figure.

(a) Oxygen consumption $\left(\mathrm{VO}_{2}\right)$ and (b) heart rate reserve (HRR) during Lokomat walking and normal gait for patients with stroke (gray) and nondisabled subjects (black). 
(30\% HRR) [12], i.e., the absolute minimum level. Furthermore, this study showed that exercise intensity of walking in the Lokomat is lower than during normal gait in severely disabled patients with stroke. To evaluate the effects of settings of the Lokomat, nondisabled subjects walked at various combinations of settings, demonstrating that the influence of settings of the Lokomat on $\mathrm{VO}_{2}$ and HR is marginal. Finally, it was demonstrated that, when walking in the Lokomat is compared with overground walking, patients with stroke responded differently to assistance of the device than nondisabled subjects.

\section{Exercise Intensity of Lokomat Walking}

Our study suggests that, based on the estimates of exercise intensity, the target training intensities (30\% HRR) were not reached for most patients with stroke when walking in the Lokomat. Nevertheless, a recent study by Chang et al. [21] showed that after only 2 wk of intervention, a group of patients with stroke training in the Lokomat had a larger improvement of $\mathrm{VO}_{2 \text { peak }}$ as measured during an incremental exercise test than a group of control patients receiving conventional therapy. Note, however, that differences in recovery of function between groups might also be responsible for an increase similar to that observed by Chang et al. [21]. This confounding factor should be taken into account during exercise tests in the (sub)acute stroke population. Nevertheless, the advantage of Lokomat therapy is the longer possible duration of therapy. This may explain the findings of Chang et al. [21]. Furthermore, in a small randomized clinical trial, Husemann et al. reported an effect of Lokomat therapy on body tissue composition, which they suggested being due to increased aerobic metabolism [22]. More research is warranted to study the effects of Lokomat therapy on cardiorespiratory fitness.

\section{Effects of Settings of Lokomat on Exercise Intensity}

Therapists have a range of settings that can be adjusted and controlled during Lokomat walking. We only investigated the three main variables: treadmill speed, BWS, and amount of assistance [23]. Krewer et al. demonstrated that using a lower BWS increased $\mathrm{VO}_{2}$ when changed from 100 percent unloading to 30 percent BWS [11]. Furthermore, they showed that neither speed nor GF had a significant effect on $\mathrm{VO}_{2}$. When compared with our study, lower levels of $\mathrm{VO}_{2}$ were found in Krewer et al. [11], which was probably due to other settings (e.g., lower speed or possibly other BWS system) or the better walking ability of participants in their study. In our study, we wanted to investigate the effect on $\mathrm{VO}_{2}$ and $\mathrm{HR}$ of various settings used during therapy. The observed significant effects were very small; therefore, it can be concluded that the effects of changing settings within the ranges used in this study are only small and the clinical relevance is therefore questionable.

Furthermore, for nondisabled subjects, exercise intensity of gait at 1.7 and $2.2 \mathrm{~km} / \mathrm{h}$ was similar for all trials performed at these speeds. We expected that the assistance of the device would decrease $\mathrm{VO}_{2}$ and HR relative to unsupported normal walking based on findings in the literature [15]. The absence of such an effect may be explained by other factors that may have counterbalanced the assistance of the device, such as the requirement to follow a prescribed gait pattern. Wezenberg et al. showed that enforcing a normal step pattern increased metabolic energy cost of walking during treadmill walking [24]. It seems plausible that similar mechanisms are responsible for the results in the present study.

\section{Exercise Intensity During Walking in Patients with Stroke Versus Nondisabled Subjects}

We found a difference in the way patients with stroke responded to the assistance of the Lokomat device compared with nondisabled subjects. Patients with stroke showed a lower $\mathrm{VO}_{2}$ and \%HRR during Lokomat walking, whereas nondisabled subjects showed higher $\mathrm{VO}_{2}$ and \%HRR during Lokomat walking than during normal treadmill walking at $0.7 \mathrm{~km} / \mathrm{h}$. These results are probably mostly due to observations already described in the literature that at similar speeds, hemiparetic walking is more energy demanding than nondisabled walking, with growing disparity with more affected hemiparetic gait [25]. The Figure shows that the differences between exercise intensity of walking became smaller between subject groups when walking in the Lokomat compared with normal gait. There was no significant difference between patients with stroke and nondisabled subjects during walking in the Lokomat. These findings confirm what Krewer et al. concluded [11]: that for a given walking condition, patients performed similarly to nondisabled subjects, indicating that, contrary to overground walking, cardiorespiratory responses of nondisabled subjects during Lokomat walking are similar under similar circumstances. 


\section{Study Limitations}

Limitations of this study are the differences between patients with stroke in settings during Lokomat walking and the difference in overground walking speed for patients with stroke compared with nondisabled subjects. These differences may increase variability when patients with stroke are compared with the nondisabled subjects, thereby decreasing the power of the statistics. However, when the two-way $(2 \times 2)$ ANOVA was repeated with data from the other Lokomat trials and the $1.2 \mathrm{~km} / \mathrm{h}$ treadmill trial of nondisabled subjects (not shown), the results were the same as reported. The conclusion for the differences between patients with stroke and nondisabled subjects remains unaltered.

It is possible that the exercise intensity of Lokomat walking might still be somewhat higher with more sophisticated settings (such as asymmetrical settings) over the levels recorded in our study. By using voluntary efforts, exercise intensity can also be increased as demonstrated by Jack et al. [26-27]. They showed that in patients with incomplete spinal cord injuries, $\mathrm{VO}_{2}$ can increase markedly when subjects actively push against the robotic orthoses while walking. It is unclear whether this can also be achieved by severely disabled patients with stroke; however, it can be argued that the already altered muscle activity during walking in the Lokomat would be further changed in naturally occurring muscle activation patterns in this study [28].

We instructed patients with stroke (and nondisabled subjects) to walk as normally as possible and follow the prescribed gait pattern. For severely affected patients, further decrease of the BWS and/or GF will most likely not be possible because the prescribed gait pattern will not be followed properly; the precautions present in the Lokomat will intervene by stopping the device to an immediate standstill when there is too much deviation from the prescribed gait pattern. Furthermore, walking with more challenging settings may not be perceived as comfortable and it remains to be seen whether patients are still capable and willing to walk for $\geq 20 \mathrm{~min}$ at these more challenging Lokomat settings.

The conclusions of this study do not necessarily extrapolate to other robot-assisted devices. However, a few studies similar to our present study have been recently performed with a similar device [29-30]. In line with the previous discussion, these studies showed that only with the right settings is it possible to train patients with stroke at intensities sufficiently high for aerobic training effects.

\section{CONCLUSIONS}

From this study, it can be concluded that exercise intensity during Lokomat walking is light and below ACSM-recommended values to improve aerobic fitness. Furthermore, changing settings within certain ranges prescribed and used for severely disabled patients has only a small influence on exercise intensity.

Although our results suggest that the exercise intensity with Lokomat walking is most likely insufficient to elicit an aerobic training effect, there are indications that low-intensity training (at 30\% HRR) may increase peak aerobic capacity [31], and that in patients with stroke, Lokomat training might improve aerobic capacity [21] and body tissue composition [22]. These inconsistencies warrant further research to study the effects of training in the Lokomat on aerobic capacity and further investigation on how severely affected patients can exercise in the Lokomat at higher exercise intensities using other combinations of settings.

\section{ACKNOWLEDGMENTS}

\section{Author Contributions:}

Study concept and design: M. P. M. van Nunen, K. H. L. Gerrits, A. de Haan, T. W. J. Janssen.

Acquisition of data: M. P. M. van Nunen.

Analysis and interpretation of data: M. P. M. van Nunen, K. H. L. Gerrits, A. de Haan.

Drafting of manuscript: M. P. M. van Nunen, K. H. L. Gerrits. Critical revision of manuscript for important intellectual content: M. P. M. van Nunen, K. H. L. Gerrits, A. de Haan, T. W. J. Janssen. Statistical analysis: M. P. M. van Nunen.

Obtained funding: K. H. L. Gerrits, A. de Haan, T. W. J. Janssen. Administrative, technical, or material support: K. H. L. Gerrits, A. de Haan, T. W. J. Janssen.

Study supervision: K. H. L. Gerrits, A. de Haan, T. W. J. Janssen.

Financial Disclosures: The authors have declared that no competing interests exist.

Funding/Support: This material was based on work supported by the Dutch Heart Foundation (Hartstichting, grant 07.21). The study was conducted at Amsterdam Rehabilitation Research Center/Reade, Amsterdam, the Netherlands.

Additional Contributions: We thank Femke Hoekstra and Martine Crins for their assistance with data acquisition. 
Institutional Review: The study protocol was approved by the local ethics committee. All participants provided written informed consent before enrolling in the study.

Participant Follow-Up: The authors do not plan to inform participants of the publication of this study.

\section{REFERENCES}

1. Michael KM, Allen JK, Macko RF. Reduced ambulatory activity after stroke: the role of balance, gait, and cardiovascular fitness. Arch Phys Med Rehabil. 2005;86(8): 1552-56. [PMID:16084807] http://dx.doi.org/10.1016/j.apmr.2004.12.026

2. Macko RF, Smith GV, Dobrovolny CL, Sorkin JD, Goldberg AP, Silver KH. Treadmill training improves fitness reserve in chronic stroke patients. Arch Phys Med Rehabil. 2001;82(7):879-84. [PMID:11441372] http://dx.doi.org/10.1053/apmr.2001.23853

3. Ivey FM, Hafer-Macko CE, Macko RF. Exercise training for cardiometabolic adaptation after stroke. J Cardiopulm Rehabil Prev. 2008;28(1):2-11. [PMID:18277823]

4. MacKay-Lyons MJ, Makrides L. Cardiovascular stress during a contemporary stroke rehabilitation program: is the intensity adequate to induce a training effect? Arch Phys Med Rehabil. 2002;83(10):1378-83. [PMID:12370872] http://dx.doi.org/10.1053/apmr.2002.35089

5. Colombo G, Wirz M, Dietz V. Driven gait orthosis for improvement of locomotor training in paraplegic patients. Spinal Cord. 2001;39(5):252-55. [PMID:11438840] http://dx.doi.org/10.1038/sj.sc.3101154

6. Wendel-Vos GC, Schuit AJ, Feskens EJ, Boshuizen HC, Verschuren WM, Saris WH, Kromhout D. Physical activity and stroke. A meta-analysis of observational data. Int J Epidemiol. 2004;33(4):787-98. [PMID:15166195] http://dx.doi.org/10.1093/ije/dyh168

7. Kuys S, Brauer S, Ada L. Routine physiotherapy does not induce a cardiorespiratory training effect post-stroke, regardless of walking ability. Physiother Res Int. 2006; 11(4):219-27. [PMID:17236529] http://dx.doi.org/10.1002/pri.344

8. Hidler J, Nichols D, Pelliccio M, Brady K, Campbell DD, Kahn JH, Hornby TG. Multicenter randomized clinical trial evaluating the effectiveness of the Lokomat in subacute stroke. Neurorehabil Neural Repair. 2009;23(1):5-13. [PMID:19109447] http://dx.doi.org/10.1177/1545968308326632

9. Schwartz I, Sajina A, Neeb M, Fisher I, Katz-Luerer M, Meiner Z. Locomotor training using a robotic device in patients with subacute spinal cord injury. Spinal Cord. 2011;49(10):1062-67. [PMID:21625239]

http://dx.doi.org/10.1038/sc.2011.59
10. Mehrholz J, Werner C, Kugler J, Pohl M. Electromechanical-assisted training for walking after stroke. Cochrane Database Syst Rev. 2007;(4):CD006185.

[PMID:17943893]

11. Krewer C, Müller F, Husemann B, Heller S, Quintern J, Koenig E. The influence of different Lokomat walking conditions on the energy expenditure of hemiparetic patients and healthy subjects. Gait Posture. 2007;26(3):372-77. [PMID:17113774] http://dx.doi.org/10.1016/j.gaitpost.2006.10.003

12. American College of Sports Medicine. ACSM's guidelines for exercise testing and prescription. 8th ed. Baltimore (MD): Wolters Kluwer/Lippincott Williams \& Wilkins; 2010.

13. Waters RL, Mulroy S. The energy expenditure of normal and pathologic gait. Gait Posture. 1999;9(3):207-31. [PMID:10575082] http://dx.doi.org/10.1016/S0966-6362(99)00009-0

14. Griffin TM, Roberts TJ, Kram R. Metabolic cost of generating muscular force in human walking: insights from loadcarrying and speed experiments. J Appl Physiol. 2003;95(1): 172-83. [PMID:12794096]

15. Danielsson A, Sunnerhagen KS. Oxygen consumption during treadmill walking with and without body weight support in patients with hemiparesis after stroke and in healthy subjects. Arch Phys Med Rehabil. 2000;81(7):953-57.

[PMID:10896011] http://dx.doi.org/10.1053/apmr.2000.6283

16. Gottschall JS, Kram R. Energy cost and muscular activity required for propulsion during walking. J Appl Physiol. 2003;94(5):1766-72. [PMID:12506042]

17. Holden MK, Gill KM, Magliozzi MR, Nathan J, PiehlBaker L. Clinical gait assessment in the neurologically impaired. Reliability and meaningfulness. Phys Ther. 1984; 64(1):35-40. [PMID:6691052]

18. Holden MK, Gill KM, Magliozzi MR. Gait assessment for neurologically impaired patients. Standards for outcome assessment. Phys Ther. 1986;66(10):1530-39. [PMID:3763704]

19. Blum L, Korner-Bitensky N. Usefulness of the Berg Balance Scale in stroke rehabilitation: a systematic review. Phys Ther. 2008;88(5):559-66. [PMID:18292215] http://dx.doi.org/10.2522/ptj.20070205

20. Pollock A, Baer G, Langhorne P, Pomeroy V. Physiotherapy treatment approaches for the recovery of postural control and lower limb function following stroke: a systematic review. Clin Rehabil. 2007;21(5):395-410. [PMID:17613560] http://dx.doi.org/10.1177/0269215507073438

21. Chang WH, Kim MS, Huh JP, Lee PK, Kim YH. Effects of robot-assisted gait training on cardiopulmonary fitness in subacute stroke patients: a randomized controlled study. Neurorehabil Neural Repair. 2012;26(4):318-24. 
[PMID:22086903]

http://dx.doi.org/10.1177/1545968311408916

22. Husemann B, Müller F, Krewer C, Heller S, Koenig E. Effects of locomotion training with assistance of a robotdriven gait orthosis in hemiparetic patients after stroke: a randomized controlled pilot study. Stroke. 2007;38(2):34954. [PMID:17204680] http://dx.doi.org/10.1161/01.STR.0000254607.48765.cb

23. Hesse S, Werner C, Paul T, Bardeleben A, Chaler J. Influence of walking speed on lower limb muscle activity and energy consumption during treadmill walking of hemiparetic patients. Arch Phys Med Rehabil. 2001;82(11):1547-50. [PMID:11689974] http://dx.doi.org/10.1053/apmr.2001.26607

24. Wezenberg D, de Haan A, van Bennekom CA, Houdijk H. Mind your step: metabolic energy cost while walking an enforced gait pattern. Gait Posture. 2011;33(4):544-49. [PMID:21330135] http://dx.doi.org/10.1016/j.gaitpost.2011.01.007

25. Zamparo P, Francescato MP, De Luca G, Lovati L, di Prampero PE. The energy cost of level walking in patients with hemiplegia. Scand J Med Sci Sports. 1995;5(6):348-52. [PMID:8775719] http://dx.doi.org/10.1111/j.1600-0838.1995.tb00057.x

26. Jack LP, Purcell M, Allan DB, Hunt KJ. Comparison of peak cardiopulmonary performance parameters during robotics-assisted treadmill exercise and arm crank ergometry in incomplete spinal cord injury. Technol Health Care. 2010;18(4-5):285-96. [PMID:21209477]

27. Jack LP, Purcell M, Allan DB, Hunt KJ. The metabolic cost of passive walking during robotics-assisted treadmill exercise. Technol Health Care. 2011;19(1):21-27. [PMID:21248409]

28. Hidler JM, Wall AE. Alterations in muscle activation patterns during robotic-assisted walking. Clin Biomech (Bris- tol, Avon). 2005;20(2):184-93. [PMID:15621324]

http://dx.doi.org/10.1016/j.clinbiomech.2004.09.016

29. Mehrholz J, Werner C, Hesse S, Pohl M. Immediate and long-term functional impact of repetitive locomotor training as an adjunct to conventional physiotherapy for nonambulatory patients after stroke. Disabil Rehabil. 2008; 30(11):830-36. [PMID:17852272] http://dx.doi.org/10.1080/09638280701419326

30. David D, Regnaux JP, Lejaille M, Louis A, Bussel B, Lofaso F. Oxygen consumption during machine-assisted and unassisted walking: a pilot study in hemiplegic and healthy humans. Arch Phys Med Rehabil. 2006;87(4):482-89. [PMID:16571386] http://dx.doi.org/10.1016/j.apmr.2005.11.034

31. van Den Berg R, De Groot S, Swart KM, Van Der Woude LH. Physical capacity after 7 weeks of low-intensity wheelchair training. Disabil Rehabil. 2010;32(21):1717-21. [PMID:20187736] http://dx.doi.org/10.3109/09638281003649961

Submitted for publication January 5, 2012. Accepted in revised form April 17, 2012.

This article and any supplementary material should be cited as follows:

Van Nunen MP, Gerrits KH, de Haan A, Janssen TW. Exercise intensity of robot-assisted walking versus overground walking in nonambulatory stroke patients. J Rehabil Res Dev. 2012;49(10):1537-46.

http://dx.doi.org/10.1682/JRRD.2011.12.0252

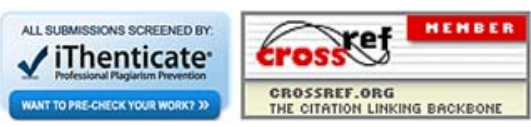

